\title{
REPENSANDO O FALSIFICACIONISMO DE KARL POPPER
}

\author{
Pedro Augusto Ciola de Almeida ${ }^{88}$
}

\begin{abstract}
RESUMO
Popper viu no falsificacionismo a principal característa das teorias científicas e o usou como plataforma da sua compreensão falibilista do saber. A ciência não extrai a verdade de uma experiência, mas sim uma corroboração, que não garante que em ulteriores testes será corroborada. Popper interpretou a ciência como tentativa e erro, mas a história da ciência mostra que existem teorias rivais que competem para explicar a natureza, não sendo possível simplesmente conjecturar e refutar. Seu falsificacionismo não o levou para o falibilismo, mas sim para o provisionismo.
\end{abstract}

Palavras-chave: Falsificacionismo; Falibilismo; Newton; Einstein; Conjectura.

\begin{abstract}
Popper saw in falsificationism the main characteristic of scientific theories and used it as a platform for his falibilistic understanding of knowledge. Science does not extract the truth from an experience, but a corroboration, which does not guarantee that in later tests it will be corroborated. Popper interpreted science as trial and error, but the history of science shows that there are rival theories competing to explain nature, and it is not possible to simply conjecture and refute. Their falsificationism did not lead to fallibilism, but to provisionism.
\end{abstract}

Keywords: Falsificationism; Fallibilism; Newton; Einstein; Conjecture.

\section{INTRODUÇÃO}

Karl Popper viveu no tumultuado século XX marcado pelas duas guerras mundiais, com o agravante para ele por ser judeu residente na Europa, muitos de sua família foram mortos nos campos de concentração, teve que migrar para alguns países até se estabelecer definitivamente no Reino Unido onde viveu a maior parte de sua vida e naturalizou-se.

Amplamente conhecido como filósofo da ciência sua teoria do conhecimento ganhou admiradores no mundo inteiro e gerou uma nova forma de se pensar a ciencia. O seu contexto é neopositivista, Popper concorda com Carnap em diversos elementos sobre filosofia da ciência, mas há discordâncias relevantes fazendo com que Popper não pudesse trilhar o caminho neopositivista.

Popper escreveu que Sócrates e Einstein o fizeram um falibilista, o primeiro pela sua modéstia intelectual, o segundo por considerar normal que uma teoria física pode ter uma aproximação melhor a

\footnotetext{
88 Mestre em filosofia pela Pontifícia Universidade Católica de São Paulo (PUC-SP). Docente do Centro Universitário Assunção - UNIFAI, e Pontifícia Universidade Católica de São Paulo (PUC-SP).
}

Revista Lumen, v. 5, $\mathrm{n}^{\circ}$ 9, Jan./Jun. - 2020 - ISSN: 2447-8717 
realidade do que outra e se refutada pela experiência é descartada, aí encontra-se o estatuto do método científico (POPPER, 2002, p. 37-39).

Popper viu na possibilidade de falsificação a principal caracteristica de uma teoria científica, se essa teoria passa no teste não significa que ela é verdadeira, mas que foi corroborada e não garante sucesso em testes ulteriores.

O problema é que o falsificacionismo possui uma abordagem muito simplista diante do labirinto da natureza, ciência não é apenas uma teoria ou um conjunto de teorias prontas para serem falsificadas, uma ciência cresce com diversas anomalias e a história da ciência mostra que não se pode eliminar uma teoria prematuramente por conta de anomalias, pois corre-se o risco de matá-la antes dela motrar seu poder heurístico ${ }^{89}$.

\section{POPPER}

Karl Raimund Popper nasceu em Viena no ano de 1902, estudou matemática, física e filosofia; com físicos como Wirtinger, Furtwangler e o matemático Hans Hahn. Sua tese de doutoramento em filosofia é de 1928 com o tema sobre a questão do método da psicologia do pensamento, com aprovação do psicólogo Karl Buhler.

Sendo Popper de origem judaica, a ascensão do nazismo, o fez emigrar em 1937 para a Nova Zelândia onde foi professor de filosofia na universidade de Canterbury, em Christchurch; dezesseis parentes seus não tiveram a mesma sorte e foram levados para os campos de extermínio

Em 1935, Popper publicou uma de suas obras fundamentais a Lógica da descoberta cientifica, ganhando considerável notoriedade na pesquisa da teoria do conhecimento, junto com sua publicação de 1963: Conjecturas e Refutações, tornaram “talvez o maior filósofo da ciência do século XX” (REALE, 2006, p. 138).

É fundamental tratar do contexto que emergiu a filosofia da ciência popperiana, neste artigo é preciso salientar dois aspectos importantes: o positivismo e a nova ciência de Albert Einstein.

\section{CÍRCULO DE VIENA}

Entre as duas grandes guerras Viena foi a capital de um dos centros mais importantes do método cientifico: desenvolvendo as ideias neopositivistas. Uma vez que, em Viena, o liberalismo foi o modelo econômico predominante e diverso da maioria das universidades alemãs, devido a influência católica, a

${ }^{89}$ Ver o item 7 - Limites do falsificacionismo

Revista Lumen, v. 5, $\mathrm{n}^{\circ}$ 9, Jan./Jun. - 2020 - ISSN: 2447-8717 
universidade de Viena se manteve longe do idealismo ${ }^{90}$. Com efeito, segundo um de seus membros, Otto Neurath, a mentalidade escolástica semeou a base de uma abordagem lógica das questões filosóficas.

Quando o físico e filósofo Moritz Schlick veio para a universidade de Viena, para ocupar a cátedra que outrora foi de Ernst Mach, o Círculo de Viena teve oficialmente seu início em 1922, quatro anos depois chegou Rudolf Carnap uniu-se ao matemático Hans Hahn e ao sociólogo e economista Otto Neurath. Foi o matemático Kurt Reidemeister que propôs a leitura e debate do Tractatus logico-philosophicus de Wittgenstein.

Em 1929, foi publicado pelo Círculo de Viena: A concepşão cientifica do mundo, que pode ser resumido

59 pela busca de uma ciência unificada, para atingir essa grande pretensão, o meio consiste no método lógico de Peano, Frege, Whitehead e Russell. Isso resultaria na eliminação da metafísica, uma contribuição para se entender melhor os conceitos, as teorias da ciência empírica e os fundamentos da matemática.

Do Círculo de Viena surgiu o princípio de verificação para separar as asserções sensatas das ciências empíricas das asserções insensatas da metafísica. Só valem as proposições que podem ser verificadas empiricamente ou factuais, de modo que a matemática e a lógica são convenções estipuladas e não podem dizer nada sobre o mundo. A metafísica, a ética e a religião utilizando de conceitos que não podem ser factualmente verificáveis não passam de pseudoconceitos.

Popper participou de alguns encontros do Círculo de Viena e teve admiração pelos sérios trabalhos que lá foram empreendidos, isso fez com que diversos filósofos pensassem que Popper fosse um neopositivista. No livro $A$ disputa positivista na sociologia alemã editado por Theodore Adorno, professores de filosofia e sociologia, como o próprio Adorno e Jugens Habermas, criticam a filosofia popperiana chamando-a de positivista.

Popper e os neopositivistas acreditaram na unidade do método científico, todas as ciências devem usar os mesmos métodos, acreditaram no crescimento cumulativo da ciência. Elaborar hipóteses, deduzir consequências, testá-las empiricamente: trata-se do método popperiano de conjectura e refutação. Popper e os nepositivistas entenderam que a ciência natural é o melhor exemplo de pensamento racional, eles compreenderam que a ciência tende a teoria verdadeira do universo.

Porém, o próprio Popper, rejeitou ser chamado de neopositivista e diferentemente dos neopositivistas, Popper defendeu que a ciência tenta descobrir explicações e causas, elabora conjecturas, o conhecimento é falível, tenta descartar a indução, ele não possuía a fixação positivista com a observação e com os dados puros dos sentidos, ele considerava a teoria dos significados sem importância para a filosofia da ciência, Popper defendeu a falsificação como critério para distinguir ciência de não ciência e a metafísica poder ser o primeiro passo para a formação de conjecturas mais ousadas.

${ }^{90}$ Popper valorizou a influência da Igreja Católica em sua terra natal o preservou do idealismo (como uma ilha num dilúvio). 
Por um tempo o Círculo de Viena adotou o princípio de verificação empírica para distinguir o que é ciência e o que são convenções e pseudoconceitos. Popper entendeu que a verificação não pode ser um critério adequado para distinguir ciência de não ciência, apresentando duas críticas principais:

- Muitas verificações empíricas não bastam para fundamentar logicamente leis universais.

- A necessidade de um enunciado ser reduzível a um enunciado particular de verificação empírica para ser científico acabou com a metafísica, mas os neopositivistas na ânsia de acabar com a metafísica, aniquilaram com ela a ciência natural, pois "as leis cientificas também não podem ser logicamente reduzidas a enunciados elementares de experiência” (POPPER, 2007, p. 37).

Diversos motivos fizeram com que, o critério de verificação, passasse a encontrar resistência entre alguns membros do próprio Círculo de Viena. Nos Estados Unidos, Carnap, deixou de falar verificabilidade para usar controlabilidade e Wittgenstein utilizou jogos de linguagem.

\section{A SUPERAÇÃO DO NEOPOSITIVISMO}

É possível traçar semelhanças entre Popper e o pensamento neopositivista, mas é possível mostrar muitas diferenças, por isso ele não foi um neopositivista. O próprio Otto Neurath considerou Popper a oposição oficial do Círculo de Viena (POPPER, 2008, p. 29).

Em sua autobiografia Unended Quest, Popper assumiu a responsabilidade pela morte do neopositivismo: “Todos sabem hoje em dia que o positivismo lógico está morto. Mas ninguém parece suspeitar que pode haver uma questão a ser feita: quem é o responsável? Ou melhor quem fez isso? Temo que devo admitir a responsabilidade" (POPPER, 2002, p. 99).

Vale ressaltar que a ascensão do nazismo fez com que os membros do Círculo de Viena tivessem que fugir para diferentes países atrapalhando muito a continuação dos trabalhos. Além disso, filósofos como Peirce e Dewey contribuíram para o fim do neopositivismo, a obra Dois dogmas do empirismo de Quine é considerada fundamental da filosofia pós-neopositivista.

Popper deu significativa contribuição para a teoria do conhecimento e a filosofia da ciência tomarem novos rumos, epistemólogos pós-popperianos como Lakatos, Paul Feyerabend, Larry Laudan e Thomas Kuhn não deixam dúvida da profunda mudança.

\section{A INFLUÊNCIA DE ALBERT EINSTEIN SOBRE O SEU PENSAMENTO}


Nas nossas experiências cotidianas a física de Newton explica admiravelmente os fenômenos físicos. Porém, em escala atômica, altas velocidades e intensa gravidade pesquisas realizados no último século colocaram a física clássica em cheque.

Contrastes entre as teorias de Newton e Maxwell despertavam interesse entre alguns físicos. Foi em 1905 que Albert Einstein publicou a teoria da relatividade estrita, sobre a eletrodinâmica dos corpos em movimento, reformulando os conceitos tradicionais de espaço e tempo, matéria e energia da física clássica.

Newton imaginou o espaço como um palco vazio, o espaço é a moldura para tudo o que acontece no cosmos. O palco de Newton era passivo, absoluto, eterno e imutável. A ação não afetava o palco e o palco não afetava a ação.

A ciência de Newton permitiu entender a maior parte do movimento das nossas experiências cotidianas e é estudada até hoje. Suas fórmulas explicam desde o movimento de queda de um objeto, a órbita da Terra em torno do Sol; seja para lançar satélites ou para posar aviões.

O palco de Newton foi um sucesso e ficou sob os holofotes por mais de duzentos anos, até as primeiras décadas do século XX com o surgimento de novas ideias que o fizeram chacoalhar. Essas ideias foram apresentadas por um jovem chamado Albert Einstein.

Einstein cresceu na alvorada da eletricidade, dando origem a novas tecnologias que Newton jamais imaginou. Einstein não se interessava pela luz do poste ou as lâmpadas, mas pela própria natureza da luz. A fascinação de Einstein sobre a velocidade da luz, o levou a derrubar o conceito de Newton sobre o espaço e o tempo.

Sobretudo, surgiu a famosa lei que está na base de tantos fenômenos nucleares: $E=\mathrm{mc}^{2}$. Onze anos depois, Einstein publicou a teoria da relatividade geral superando e generalizando a anterior.

A equação de Einstein mostrava que energia é o mesmo que matéria, mas de forma diferente. A matéria pode ser convertida em uma grande quantidade de energia. Esse é o fundamento da energia nuclear e das armas nucleares, ambas controlam a energia que pode ser liberada interferindo no núcleo dos átomos.

A luz sempre viaja á mesma velocidade, independentemente da velocidade em que o observador está se movendo. Um feixe de luz sempre está a $299.792 .458 \mathrm{~m} / \mathrm{s}$. Tal constatação sobre a velocidade constante da luz, levou Einstein a pensar que tempo e espaço trabalham juntos. Significa dizer que tempo e espaço se ajustam constantemente permitindo que a velocidade da luz seja sempre $1.080 .000 \mathrm{Km} / \mathrm{h}$.

Ao aproximar da velocidade da luz o tempo desacelera e a distância se contrai. Essa tese ficou provada em 1971, ao levar um relógio atômico em um avião registrou um tempo ligeiramente mais curto do que um relógio idêntico deixado estacionado no solo.

Newton sabia que a gravidade é uma força que atrai os objetos entre si e as leis que descreveu preveem essa força com uma precisão fantástica. Porém, como a gravidade realmente funciona? Como a Terra atrai a Lua? As leis de Newton não davam nenhuma explicação para isso. 
O segredo da gravidade está na natureza do espaço-tempo que pode se esticar como um tecido. A Lua se move ao longo de uma curva no espaço-tempo causada pela Terra. Trata-se de uma ruptura com Newton. Depois de Einstein, o palco não pode ser mais pensado como estático, mas sim dinâmico.

A matéria curva o tecido espaço-temporal como bolas sobre um lençol causando um afundamento nela. O modo como outros objetos e a luz movem-se diante dessa inclinação chamamos de gravidade.

Quando o astrônomo Arthur Eddington e seus colaboradores confirmaram parte da teoria de Einstein mostrando que a gravidade pode curvar a luz, Einstein virou estrela internacional no mundo científico. Popper participou de palestras proferidas por Einstein e algumas vezes teve oportunidade de conversar com ele sobre ciência e filosofia, "tornou-se uma influência dominante sobre meu pensamento" (POPPER, 2002, p. 37). Popper entendeu que a epistemologia e a filosofia da ciência precisavam ser reformuladas.

\section{BINÔMIO CIENTIFICO-FILOSÓFICO: NEWTON-KANT, EINSTEIN-POPPER}

No mesmo ano de falecimento de Galileu Galilei nasceu, no dia de Natal, Isaac Newton, o cientista que levou a física moderna ao seu cume. O livro mais famoso de Newton é Philosophiae naturalis principia mathematica, de 1687, uma publicação que marcou profundamente a filosofia.

$\mathrm{O}$ alcance de seu pensamento influenciou muito o empirismo inglês e o iluminismo (especialmente o francês): a razão limitada e controlada pela experiência, bem como o deísmo foram duas heranças principais que o iluminismo herdou de Newton. A física newtoniana não versa sobre a essência dos fenômenos, mas volta-se para os fenômenos procurando provar as leis de seu funcionamento. Para Newton todas as causas são mecânicas, exceto a Primeira, de modo que todos os fenômenos podem ser explicados pela sua mecânica.

Sem a "compreensão da imagem da ciência newtoniana, é verdadeiramente impossível compreender a Crítica da razão pura de Kant” (REALE, 2005a, p. 233). Kant publicou um livro, em 1755, chamado $A$ teoria dos céus tem um subtítulo interessante com o nome de Um ensaio sobre a constituição e a origem mecânica do universo, tratadas de acordo com os princípios de Newton.

Quando "Kant fala de ciência natural, estava quase invariavelmente a pensar na mecânica celeste de Isaac Newton" (POPPER, 2006, p. 253), a famosa emoção relatada na Crítica da razão prática pelo céu estrelado acima de mim de Kant é a comoção pelo universo relógio de Newton (Ibidem, p. 137).

O modo como Kant pôs a física de Newton em sua filosofia foi engenhosa: assim como Copérnico afirmou que não é o Sol que gira em torno da Terra, mas o contrário, Kant introduziu o que chamou de Revolução Copernicana na teoria do conhecimento, não é o objeto que se impõe ao sujeito como essência, mas sim o sujeito que impõe suas leis aos objetos. Que leis são essas? Leis inerentes ao 
sujeito humano presentes no intelecto e na sensibilidade, em outras palavras, as leis de Newton (Ibidem, p. 75 e $262-263)$.

O conhecimento, episteme, para Kant é possível já que o sujeito é ativo os dados que se apresentam aos nossos sentidos são submetidos às leis matemáticas que são inerentes ao sujeito. Para Kant a ciência newtoniana era absolutamente verdadeira e essa crença manteve-se inabalável até o final do século XIX (POPPER, 2006, p. 134).

A crítica de David Hume de que não é possível ter conhecimento seguro a partir de leis universais ficou esquecida pelo sucesso da ciência de Newton e articulação filosófica de Kant. Escreveu Kant no final da Critica da razão prática: “[...] uma visão tão clara da estrutura do universo, que se manterá inalterada para todo o sempre. E, embora haja esperança de que a nossa visão se expanda ainda mais por uma contínua observação, não haverá que temer nunca qualquer retrocesso" (KANT apud POPPER, 2006, p. 134)

Popper admirava Einstein não apenas pela sua genialidade, mas também pela sua postura diante de uma teoria cientifica. Assistindo uma palestra de Einstein em Viena, no ano de 1919, Popper ficou muito impressionado, porque Einstein proclamou a sua teoria gravitacional insustentável, se não resistisse a alguns testes.

Trata-se de sua abertura à refutação experimental, aí residia o estatuto da cientificidade de uma teoria. Einstein considerava natural que uma teoria física pudesse apontar para outra teoria mais bem sucedida, e se uma teoria cientifica falhasse em certos testes não é sustentável (POPPER, 2002, p. 38-39).

Uma teoria não falsificável pela experiência não é uma teoria cientifica, a "irrefutabilidade não é uma virtude da teoria (como as pessoas muitas vezes julgam), mas sim um defeito" (POPPER, 2006, p. 59). A busca por uma teoria capaz de explicar tudo ou de dar um conhecimento imutável já é um sinal para Popper de que há algo errado.

Importante ressaltar que o próprio Popper reconheceu em seu tempo a dificuldade de entender as repercussões da teoria da Relatividade para a mecânica newtoniana, por momento não teve muita clareza: "É sempre difícil interpretar as teorias mais recentes" (Ibidem, p. 161).

Outro campo de pesquisa que colocou a mecânica newtoniana em cheque foi o estudo sobre os fenômenos de interação entre a matéria e as radiações (REALE, 2006, p. 102-103). Max Planck cunhou o termo "Quantum" para o problema do "corpo negro" (um objeto que absorve toda energia radiante transformando em calor) a emissão de energia de um corpo negro na variação da temperatura é “incompatível com a termodinâmica e, portanto, com a mecânica clássica” (Ibidem, p. 104).

Não é o caso de narrar detalhadamenre o desenvolvimento da física nos dois campos de pesquisa tratados acima (quantico e astronômico), mas importa para este artigo chegar em Heisenberg com o princípio de indeterminação de 1927: a "causalidade rigorosa dos fenômenos físicos era negada pela primeira vez, em virtude da impossibilidade de prever com exatidão o comportamento das partículas atômicas" (ABBAGNANO, 2007, p. 538). 
Desse modo, segundo Werner Heisenberg, teórico da física quântica e Nobel de física em 1933, a física não nos fornece mais "uma imagem da natureza, mas uma imagem das nossas relações com a natureza" (HEISENBRG apud ABBAGNANO, 2007, p. 539).

A respeito do exposto acima, a ciência de Newton ainda que confirmada pelas observações, não era resultado delas, mas sim do nosso próprio modo de pensar, das nossas tentativas de ordenar o que chega pelos sentidos (POPPER, 2006, p. 247-248). Uma vez que, a física de Newton precisou ser corrigida em muitos ambientes ${ }^{91}$, Popper lembrou de seu articulador na filosofia e também propôs uma correção.

A fé de Kant na sua teoria do espaço e do tempo como um quadro de referência intuitivo foi confirmada quando encontrou nela a chave para a solução de um segundo problema. Este era o problema da validade newtoniana, em cuja absoluta e inquestionável verdade Kant acreditava, à semelhança, aliás, de todos os físicos seus contemporâneos (POPPER, 2006, p. 247).

É preciso reconhecer a genialidade de Kant em colocar o sujeito ativo no processo do conhecimento, mas não significa sucesso ao impor leis a natureza, pois a maioria de nossas ideias é um fracasso e são falsificadas pela experiência (Ibidem, p. 136).

A Revolução Copernicana de Kant é um “estranho misto de absurdo e verdade” (Ibidem, p. 135). Por isso, Popper, preferiu colocar nesses termos a Revolução Copernicana: "O nosso intelecto não extrai as suas leis da Natureza, mas tenta - com graus variáveis de sucesso - impor à Natureza leis que livremente inventa" (Ibidem, p. 262).

Como agora sabemos, ou acreditamos saber, a teoria de Newton não passava de uma maravilhosa conjectura, de uma aproximação espantosamente bem conseguida. Única, na verdade, mas não como verdade divina: apenas uma invenção única do gênio humano, que não é episteme, mas pertence ao reino da doxa (Ibidem, p. 135).

Como "a ciência é falível, porque a ciência é humana" (POPPER, 1998b, p. 395), precisa constantemente ser colocada à prova e testada. Todos os enunciados científicos permanecem provisórios ou conjecturais para sempre, o ser-humano é incapaz de produzir um conhecimento no grau de episteme (POPPER, 2007, p. 308).

Quando Popper queria explicar o seu método cientifico e sua racionalidade de forma bem simples para seu alunos escrevia na lousa um esquema que chamou de esquema tetrádico: P1 $\rightarrow$ TT $\rightarrow$ EE $\rightarrow$ P2

- P1: é o problema que queremos resolver.

\footnotetext{
${ }^{91}$ Vai além das intenções deste artigo tratar das questões mais atuais da física como a matéria escura e a energia escura que compõem noventa e cinco por cento do universo, mostrando como a física de Newton versa de modo admirável para um ambiente muito restrito.
} 
- TT: é uma teoria para tentar resolver.

- EE: é uma tentativa para eliminar erros através da crítica.

- P2: é um novo problema que resulta de nossa critica

Com esse simples esquema Popper quis ensinar que a ciência é falível por ser ciência humana, a tentativa crítica de solução de um problema tem mais chance de ser malsucedida, uma teoria cientifica que passe no teste de refutações não significa que passará em ulteriores experimentos e permanentemente luta pela sobrevivência, a busca do conhecimento é sem fim (NOTTURNO, 2014, p. 47).

\section{FALSIFICACIONISMO}

Para Popper, o verificacionismo não pode servir de critério de demarcação entre ciência e não ciência. Ele não demarcou ciência e não ciência através de linguagem sensata e linguagem insensata, mas sim através do critério de falsificabilidade.

As teorias científicas não são como as matemáticas ou as metafísicas, porque são passíveis de serem falsificadas empiricamente. Por mais confirmações que se obtenha de uma teoria, ela continua sendo falsificável: jamais se exclui que em um controle posterior possa refutar uma teoria bem corroborada.

[...] só reconhecerei um sistema como empírico ou científico se ele for passível de comprovação pela experiência. Essas considerações sugerem que deve ser tomado como critério de demarcação, não a verificabilidade, mas a falseabilidade de um sistema. Em outras palavras, não exigirei que um sistema científico seja suscetível de ser dado como válido, de uma vez por todas, em sentido positivo; exigirei, porém, que sua forma lógica seja tal que se torne possível validá-lo através de recursos a provas empíricas, em sentido negativo: deve ser possível refutar, pela experiência, um sistema científico empírico. (POPPER, 2007, p. 42).

Popper viu na falseabilidade a principal característica das teorias cientificas e a transformou "na plataforma teórica da sua concepção falibilista do saber" (ABBAGNANO, 2007, p. 496).

Popper não foi o primeiro a trabalhar o termo falibilismo: "pelo que eu saiba, encontra-se pela primeira vez em Charles Sanders Peirce” (POPPER Apud REALE, 2006a, p. 83). Peirce não apenas usou o falibilismo, mas também o conceito falsificação, por isso alguns filósofos o vêm como um predecessor de Popper. O conhecimento para Peirce jamais é absoluto e uma hipótese bem verificada não é segura para sempre, detalhadamente Peirce trata da autocorreção do método científico.

Popper adotou o falibilismo entendendo-o como o procedimento que permite elaborar conjecturas e submeter a refutações empíricas, negando a pretensão de certeza absoluta na teria do conhecimento.

Revista Lumen, v. 5, $\mathrm{n}^{\circ}$ 9, Jan./Jun. - 2020 - ISSN: 2447-8717 
Para Popper, a "ciência parte, pois, de problemas e não de observações" (POPPER, 2006, p. 302), as teorias são criadas para resolver os problemas e é necessário submetê-las ao controle dos fatos. A prova ocorre extraindo consequências das teorias, se corroboram ou não. Em caso de corroboração, por momento, as teorias estão corroboradas, caso contrário a teoria é falseada, ou seja, das teorias é preciso extrair consequências que possam refutá-la pelos fatos.

Um sistema pode ser considerado cientifico se é controlado pela experiência, mas o critério de demarcação não é através de verificação e sim de falsificação, isto é, um sistema empírico precisa poder ser refutado pela experiência.

A asserção "chove ou não chove" não pode ser falsificada, mas a proposição "hoje à tarde choverá aqui" pode ser desmentida pelo sol nesse período, dessa forma uma teoria para ser cientifica precisa poder ser falsificada pelos fatos. O fato de achar dois cisnes pretos ou mil cisnes pretos não permite afirmar uma teoria de que todos os cisnes são pretos, basta achar um cisne branco para falsear a teoria.

Se uma teoria não pode ser testada em ambiente empiricamente controlável, ela não é científica. Porém, ao contrário dos neopositivistas, uma teoria metafísica não deve ser desprezada, porque uma teoria metafísica pode se tornar científica amanhã, como o heliocentrismo.

Com isso Popper quer mostrar que o que se pode aprender da experiência não é a episteme de uma teoria, mas sim a falsidade de uma hipótese. A ciência não é o saber das verdades definitivamente verificadas, mas das conjecturas no momento corroboradas.

\section{LIMITES DO FALSIFICACIONISMO}

Popper foi confrontado com teorias, como as de Thomas Kuhn e Imre Lakatos, demonstrando que pode acontecer de os cientistas demorarem muito tempo para abandonar uma teoria refutada pela experiência e inventam alguma hipótese de salvação; só abandonam uma teoria quando encontram outra melhor. Os "cientistas tem pele grossa (...), eles não abandonam uma teoria meramete porque fatos a contradizeram" (LAKATOS, 2001, p. 4).

Popper empreendeu um desenvolvimento da sua concepção: partiu de uma compreensão de confrontação teoria-experiência para o confronto entre teorias rivais e a experiência. Além disso, Popper teve que "suavizar" o falsificacionismo para evitar que uma teoria seja abandonada rápido demais em uma eventual refutação empírica, pode ser necessário manter duas teorias falsificadas, mas que num momento representam as únicas disponíveis.

Deve-se considerar que, diferentemente da visão de Popper, ciência não é apenas hipóteses isoladas, não é simplesmente tentativa e erro ou uma série de conjectutas prontas para serem refutadas, é muito simples pensar que a ciência opera como o exemplo dado por Popper: basta achar um cisne branco para refutar a teoria que todos os cisnes são pretos. 
A ciência do Newton não são apenas as três leis da dinâmica, mas faz parte de um programa de pesquisa cientifico que contém muitas teorias que tentam explicar o espaço, o tempo, a velocidade, o movimento dos planetas em torno do sol, a força que atrai os corpos, a gravidade.

Para Popper a ciência newtoniana é a ciência mais bem corroborada da história da humanidade, para mostrar como há anomalias nas pesquisas mais bem conceituadas peguemos o exemplo do periélio de Mercúrio.

Nas proximidades de um corpo celeste com muita massa, ocorre uma deformação do espaçotempo, o espaço-tempo fica curvo, mas conforme nos afastamos dele, a curvatura vai diminuindo até que desaparece e o tecido do espaço-tempo volta a ficar plano ${ }^{92}$. Essa curvatura tem efeitos claros na órbita de Mercúrio.

Durante séculos, astrônomos, físicos e matemáticos, como Newton e Laplace, tentaram encontrar uma explicação para o fato de que as previsões teóricas nunca batiam com as posições observadas de Mercúrio. Diante dessa anomalia o que fazer? Deve-se abandonar as teorias de Newton falsificadas pelo periélio de Mercúrio?

Várias hipóteses para solucionar essa anomalia foram criadas:

- Um planeta dentro da órbita de Mercúrio (difícil de observá-lo).

- Um satélite de Mercúrio.

- Aumentar a massa de um planeta próximo (como Vênus).

- Modificar a lei da gravidade.

A Relatividade Geral de Einstein mostrou que a origem das anomalias estava na deformação do espaço-tempo nas proximidades do Sol. Na verdade, todos os planetas do Sistema Solar apresentam o periélio, mas a do planeta Mercúrio é a maior por estar mais próximo do Sol.

Esse é um bom exemplo de como o falsificacionismo de Popper precisa ser revisto, a história da ciência está cheio de teorias que crescem envolvidas por um oceano de anomalias (LAKATOS, 2001, p. 6), não sendo possível simplesmente conjecturar e refutar.

Popper tentou construir uma filosofia da ciência sem história da ciência, uma abordagem sobre a racionalidade - como ele próprio se identificou um racionalista crítico - e não se deu conta que as teorias cientificas brigam num campo de batalha pela sobrevivência.

Diversas teorias cientificas podem conviver ao mesmo tempo tentando explicar uma anomalia, é necessário esperar quais teorias gerarão conhecimento, quais teorias conseguirão prever fenômenos, mesmo que esse percurso demore séculos.

Ao invés de se avaliar teorias para o problema a questão desloca-se para avaliar séries de teorias rivais. As teorias corroboradas e que produzem novos fatos tendem a atrair a atenção dos cientistas.

${ }^{92}$ Neste item está a explicação de Einstein para esse fenômeno: 4. A influência de Albert Einstein sobre o seu pensamento 
A admissão por Popper que a principal caracterista de uma teoria cientifica é de ser falsificável e por isso a ciência é falível, leva pensar que Popper não foi um teórico do falibilismo na ciência, mas sim do provisonismo. Admitir a falibilidade de todas as teorias cientificas sem qualificação nega a certeza da base empírica poder ser transmitida a teorias, consequentmente a "ciência não pode provar qualquer coisa" (LAKATOS, 2001, p. 12).

\section{CONSIDERAÇÕES FINAIS}

Popper entendeu uma assimetria lógica entre verificação e falsificação, milhões e milhões de verificações empíricas não tornam certas uma teoria. A teoria que todos os pedações de madeira bóiam na água pode ser falseada através de apenas um fato negativo: um pedaço de ébano não bóia na água. Uma teoria científica permanece sempre desmentível, por mais confirmada que esteja.

Ele admitiu como científico apenas um sistema que possa ser controlado pela experiência, o sistema não é verificado e sim deve passar pelo critério da falsificabilidade, um sistema científico deve poder ser refutado pela experiência, todo o conhecimento científico é entendido como conjectural.

Como Popper acredita que existe um único método científico, ele estendeu tal compreesnão para a política e a econômia. Ele toma o falibilismo como um dado antrpológico: os homens e as mulheres estão muito mais errando do que acertando.

Para Popper é necessário ter consciência que teses e propostas tem mais chances de estarem erradas do que certas, mesmo as que estão certas não é possível afirmar que em todos os casos e sempre estarão certas, por isso é preciso valorizar a opinião e a análise do outro. A pesquisa e as soluções avançam e melhoram com a participação de muitas pessoas, isso vale para a filosofia, a ciência e também para a política.

Este artigo procurou demonstrar que a história da ciência não comporta apenas conjecturas e refutações, pois há teorias rivais para explicar os fenômenos naturais, mais do que teorias há um programa de pesquisa para explicar a natureza. Anomalias não são suficientes para falsear um programa de pesquisa, porque mesmo a ciência newtoniana não foi abandonada pelos cientistas com a anomalia do periélio de Mercúrio.

Ao que parece as anomalias surgem, porque mesmo um programa de pesquisa bem corroborado versa sobre um ambiente e não consegue encontrar todos os caminhos do labirinto da natureza, sendo necessário surgir outros programas de pesquisa que vão competir para explicar anomalias surgidas no programa anterior, e, assim sucessivamente, de forma mais complexa e com explicações mais acuradas da natureza.

\section{Referências}


ABBAgnANO, Nicola. Dicionário de filosofia. 5. ed. São Paulo: Martins Fontes, 2007. 1210 p.

ANTISERI, Dario; REALE, Giovanni. História da filosofia do Humanismo a Descartes. 2. ed. v. 3. São Paulo: Paulus, 2005a. 321 p.

. História da filosofia de Spinoza a Kant. v. 4. São Paulo: Paulus, 2005b. 433 p. . História da filosofia de Frend à atualidade. v.7. São Paulo: Paulus, 2006. 264 p.

LAKATOS, Imre. The methodology of scientific research programmes. Estados Unidos da América: Cambridge University Press, 2001. 250 p.

NOTTURNO, Mark. Hayek and Popper. United States: Taylor \& Francis, 2014. 224 p.

69 POPPER, Karl. A lógica da pesquisa científica. São Paulo: Cultrix, 2007. 567 p. . A sociedade aberta e seus inimigos. 3. ed. v. 1. Belo Horizonte: Itatiaia Limitada, 1998a. 395 p. . v. 2. Belo Horizonte: Itatiaia Limitada, 1998b. 420 p. . Conjecturas e refutações. Coimbra: Almedina, 2006. 580 p. . Unended Quest. New York: Routledge Classics, 2002. 320 p. . Memories of Otto Neurath. In: SHEARMUR, Jeremy; TURNER, Piers (eds.). After the Open Society. United States: Taylor \& Francis, 2008, p. 25-30. 